\title{
Bone Mineral Content Reflects Total Body Calcium in Neonatal Miniature Piglets
}

\author{
STEVEN A. ABRAMS, ${ }^{1}$ RICHARD J. SCHANLER, HWAI-PING SHENG, HARLAN J. EVANS, \\ ADRIAN D. LEBLANC, AND CUTBERTO GARZA ${ }^{2}$ \\ USDA/ARS Children's Nutrition Research Center, and Section of Neonatology, Department of Pediatrics, Baylor \\ College of Medicine, and Texas Children's Hospital, Houston, Texas 77030
}

\begin{abstract}
We measured bone mineral content (BMC) in 18 neonatal miniature piglets by single photon absorptiometry, total body calcium (TBC) by total body neutron activation analysis, growth, and serum indices of mineral status (calcium, phosphorus, alkaline phosphatase activity). Measurements were begun on day 6 , when the piglets were weaned, and were continued to day 19 . After weaning, the piglets were assigned randomly to receive one of three diets which differed only in their concentrations of calcium and phosphorus: $\mathbf{1 0 0 \%}$ of the recommended level (diet $\mathrm{A}$ ), $60 \%$ (diet B), and $20 \%$ (diet C). No differences were observed among groups during the 19-day study, either in weight gain (48 $\pm 2 \mathrm{~g}$ /day) or increment in crown-rump length $(2.4 \pm 0.2 \mathrm{~cm} / \mathrm{wk})$. BMC correlated significantly ( $p$ $<0.001)$ with TBC at $6(r=0.83), 13(r=0.77)$, and 19 $(r=0.93)$ days. BMC correlated significantly $(p<0.001)$ with the ash weight $(r=0.87)$ and calcium content $(r=$ 0.90 ) of the corresponding tibial bone segment. Anthropometric parameters and serum indices of mineral status did not predict TBC as accurately as did BMC measurements. We observed a range in BMC measurements in this study that was similar to the range reported for infants in the 1st yr of life. The high correlation between BMC and TBC suggested that $\mathrm{BMC}$ is useful in the assessment of mineral status in infants. (Pediatr Res 24:693-695, 1988)
\end{abstract}

\section{Abbreviations}

BMC, bone mineral content

TBC, total body calcium

Ca, calcium

$P$, phosphorus

AP, alkaline phosphatase

CR, crown rump

VLBW, very low birth weight

Because of mineral deficits accumulated during hospitalization, the bones of VLBW infants often fail to mineralize ade-

Received June 6, 1988; accepted August 5, 1988.

Correspondence Richard J. Schanler, M.D., Children's Nutrition Research Center, 1100 Bates Street, Houston, TX 77030

USDA/ARS Children's Nutrition Research Center, Department of Pediatrics, Baylor College of Medicine and Texas Children's Hospital, Houston, TX. This project has been funded in part by the U.S. Department of Agriculture, Agricultural Research Service under Cooperative Agreement 58-7MNI-6-100. The contents of this publication do not necessarily reflect the views or policies of the U.S. Department of Agriculture, nor does mention of trade names, commercial products, or organizations imply endorsement by the U.S. Government.

${ }^{1}$ Current address: National Institutes of Health, Bethesda, MD 20892.

${ }^{2}$ Current address: Division of Nutritional Sciences, Cornell University, Ithaca, NY 14853. quately (1). Mineral status in such high risk infants frequently is assessed from measurements of serum biochemical parameters, e.g. $\mathrm{Ca}$ and $\mathrm{P}$ concentrations, and $\mathrm{AP}$ activity, and radiologic evaluation of long bones. Although each measurement provides useful information, none is sensitive to early mineral deficiencies (2); and the adequacy of the measurements for long term monitoring of bone mineral status of high risk VLBW infants is unknown $(3,4)$.

Single photon absorptiometry is an alternative means by which bone mineralization may be monitored. Although it has been used widely in adults to study bone diseases, experience with its application in VLBW infants is limited. In adults, the relationship between TBC measured by neutron activation analysis and BMC measured by single photon absorptiometry is variable $(5$, 6). Highly significant correlations have been documented between BMC measured by this technique and by ash weights of bones from infants and small animals (7).

We report the evaluation of an animal model used in studies of bone development. The newborn piglet was selected because l) its body weight and mineral content $(\mathrm{Ca} / \mathrm{N}$ ratio of its peripheral bones) are similar to those reported for 3rd trimester human fetus and fetal long bones $(8,9)$, and 2 ) the piglet's rapid growth rate and relatively high mineral requirement permit the manipulation of bone mineral status over short periods (10). Our objective was to determine the relationships among BMC and bone $\mathrm{Ca}$ content, total body $\mathrm{Ca}$, serum biochemical parameters of bone mineralization, and somatic growth in miniature piglets fed diets with adequate or deficient calcium and phosphorus contents.

\section{MATERIALS AND METHODS}

Experimental design. Eighteen miniature piglets from three litters (Pitman-Moore/Hanford strain, Bastrop Farms, Bastrop, TX) were studied from birth until day 19 . Piglets were born at the Baylor Animal Program facility and kept with their sows for the first 5 postnatal days. On day 6 , two piglets from each litter were assigned randomly to each of three experimental diets that differed only in their calcium and phosphorus content (Table 1): diet A (recommended levels), diet B (approximately $60 \%$ of recommended levels), and diet $\mathrm{C}$ (approximately $20 \%$ of recommended levels). Iron dextran (100 mg elemental $\mathrm{Fe}$ ) was administered intramuscularly to all piglets on day 2 . All piglets were weaned using diluted (1:1, vol/vol with water) $\operatorname{diet} A$ on day 5 . They were housed in individual cages after weaning and maintained on their respective diets until day 19 .

Body weight and $\mathrm{CR}$ length were measured on days $0,6,13$, and 19. BMC and TBC were measured on days 6,13 , and 19, and serum $\mathrm{Ca}$ and $\mathrm{P}$ concentrations and AP activity were measured on days 6 and 19. Piglets were killed on day 19 with an overdose of sodium pentobarbital. The tibial bones were removed, and BMC was measured at the mid-section. At the site 
Table 1. Dietary mineral intake

\begin{tabular}{ccccc}
\hline Diet & $\begin{array}{c}\text { Ca concen- } \\
\text { tration } \\
(\mathrm{mg} / \mathrm{liter})\end{array}$ & $\begin{array}{c}\text { Ca intake } \\
(\mathrm{mg} / \mathrm{kg} / \text { day })\end{array}$ & $\begin{array}{c}\text { P concen- } \\
\text { tration } \\
(\mathrm{mg} / \text { liter })\end{array}$ & $\begin{array}{c}\text { P intake } \\
(\mathrm{mg} / \mathrm{kg} / \text { day })\end{array}$ \\
\hline A & 2000 & 700 & 1400 & 490 \\
$\mathrm{~B}$ & 1200 & 420 & 800 & 280 \\
$\mathrm{C}$ & 400 & 140 & 250 & 90 \\
\hline
\end{tabular}

of BMC measurement, a 2-cm section from the mid-tibia was removed using a precision saw; the length of the section was determined by hand calipers $( \pm 0.05 \mathrm{~cm})$. Dry and ash weights and total $\mathrm{Ca}$ were determined on the section of mid-tibia.

Experimental diets and feeding protocol. Milk was prepared by mixing Similac PM $60 / 40$ powder (Ross Laboratories, Columbus, $\mathrm{OH}$ ), egg albumin (ICN Biochemicals, Cleveland, $\mathrm{OH}$ ), corn oil, and multivitamins (ICN Biochemicals). Xanthum gum (ICN Biochemicals) was added to stabilize the preparation. The concentrations (per liter) of nitrogen $(8.4 \mathrm{~g})$, energy $(1100 \mathrm{kcal})$, and fat $(50 \mathrm{~g})$ provided the piglets with the estimated protein and energy requirements for newborn piglets (11). Calcium lactate, (JT Baker Chemical Co., Phillipsburg, NJ) and potassium phosphate $(3 \mathrm{mmol} \mathrm{P} / \mathrm{ml}$, Abbott Laboratories, Chicago, IL) were added to diets $\mathrm{A}$ and $\mathrm{B}$ in sufficient quantities to achieve the desired levels (Table 1).

Milk was provided continuously in small stainless steel feeding bowls secured to the cage. This feeding method was chosen to reduce spillage of milk from filled bowls. The rate of infusion (350 ml/kg/day) was adjusted with an enteral feeding pump. The infusion apparatus was rinsed with deionized water every $12 \mathrm{~h}$ and changed daily. Residual milk from the feeding apparatus was collected and analyzed and averaged less than $5 \%$ of mineral delivered.

Anthropometry. Body weight was determined with a Sartorius electronic scale (Brinkman Instruments, Westbury, NY); CR length was measured with a flexible stainless-steel tape from the midpoint between the eyes to the base of the tail.

Bone mineralization and total body $C a$. $\mathrm{BMC}(\mathrm{mg} / \mathrm{cm})$ was measured by single photon absorptiometry (SP-2 scanner, Lunar Radiation Corp, Madison, WI). A single scan was performed in vivo at the mid-tibia in each hindleg, and the average BMC of the two tibiae was calculated. The in vivo site was determined as half of the distance of bone length between joints. In vitro BMC measurements were performed by surrounding the excised bone in a tissue-equivalent gel material after all tissue was removed from around the bone. Four measurements were performed over a 2-cm area of mid-tibia, and an average result was obtained. The coefficient of variation for BMC measurements is $<4 \%$ at a single site using four repeated scans in infants and in vitro bone samples with and without repositioning (12). The instrument was calibrated daily with the use of a phantom provided by the manufacturer. TBC was determined using total body neutron activation analysis. A detailed description of the system and technique have been published (13). Calibration of the system was performed before each measurement using phantoms as described (13).

Chemical measurements. The methods for determining serum $\mathrm{Ca}$ and $\mathrm{P}$ concentration, AP activity, and milk concentrations of energy, nitrogen, calcium, phosphorus, and fat have been described (14). The methods by which tibial bones were ashed and $\mathrm{Ca}$ content determined also have been reported. The entire $2-\mathrm{cm}$ bone section was ashed, and the results were expressed per $1 \mathrm{~cm}$ (13).

Statistical analyses. Correlations between parameters of mineral status were assessed using regression analyses. The significance of changes in a specified parameter over time was determined by paired $t$ test of differences between endpoint and starting value. Data are expressed as mean $\pm \mathrm{SEM}$.

\section{RESULTS}

Growth. Birth weight $(847 \pm 33 \mathrm{~g})$ and the measurements at day 6 of body weight $(1211 \pm 72 \mathrm{~g})$ and CR length $(30 \pm 0.9$ $\mathrm{cm}$ ) were similar among groups. Body weight and CR length increased in all groups of piglets between 6 and 19 days. The rate of weight gain between 6 and 19 days of age ( $48 \pm 2 \mathrm{~g} /$ day) and the increment in CR length $(2.4 \pm 0.2 \mathrm{~cm} / \mathrm{wk})$ were similar among the three groups.

$B M C$ and $T B C$. The groups had similar BMC $(115 \pm 5 \mathrm{mg} /$ $\mathrm{cm})$ and TBC $(11.2 \pm 0.4 \mathrm{~g})$ at day $6 . \mathrm{BMC}$ was significantly correlated to TBC at $6(r=0.83, p<0.001), 13(r=0.77, p<$ $0.001)$, and 19 days of age $(r=0.93, p<0.001)$ (Fig. 1). Percentage changes in BMC between 6 and 19 days also were correlated significantly to percentage changes in TBC $(r=0.77$, $p<0.001)$. Birth weight, body weight, and CR length were correlated significantly to $\mathrm{BMC}$ and $\mathrm{TBC}$ at 6 days of age. At 19 days of age, TBC, but not BMC, was correlated significantly to anthropometric measurements (Table 2).

$B M C$ and bone calcium content. In vivo BMC measurements were correlated highly with the ash weight $(\mathrm{r}=0.87, p<0.001)$ and Ca content $(r=0.90, p<0.001)$ (Fig. 2) of the corresponding tibial bone segment. In vitro BMC measurements also were correlated with ash weight $(r=0.96, p<0.001)$ and Ca content of the bone segment $(r=0.95, p<0.001)$. In vivo and in vitro BMC measurements of mid-tibial samples on day 19 were correlated with each other $(r=0.95, p<0.001)$.

Relationships among variables. Serum calcium was not correlated significantly to TBC or BMC. At 19 days of age, TBC accounted for $87 \%$ of the variability in $\mathrm{BMC}$. The relationship between BMC and TBC was independent of body weight. Although BMC and TBC were correlated with serum P concentration at 19 days (Table 2), neither serum $P$ concentration nor

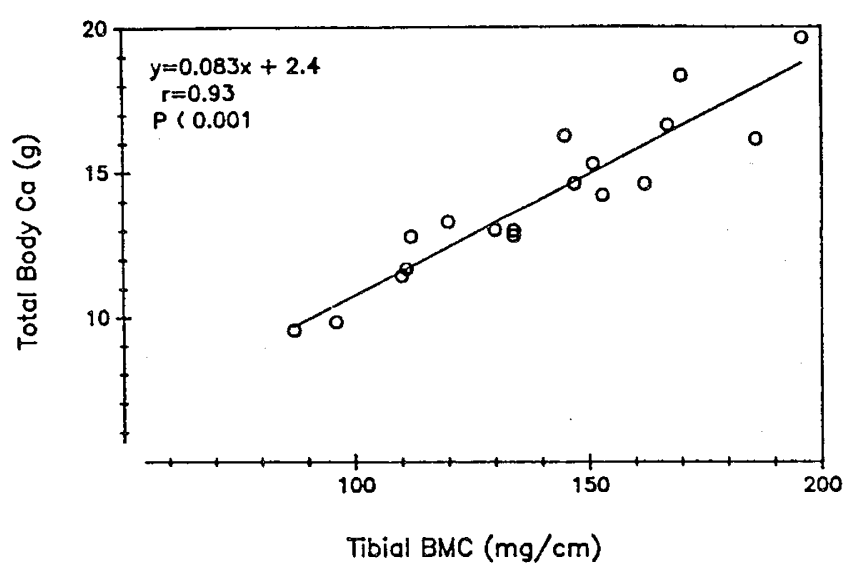

Fig. 1. Relationship between BMC and TBC in 19-day-old miniature piglets, $\mathrm{r}=0.93, p<0.001$.

Table 2. Correlation among growth, biochemical parameters, and BMC and TBC in 6- and 19-day-old miniature piglets

\begin{tabular}{lccccc}
\hline & \multicolumn{2}{c}{ 6-day-old piglets } & & \multicolumn{2}{c}{ 19-day-old piglets } \\
\cline { 2 - 3 } \cline { 5 - 6 } \cline { 5 - 6 } & BMC & TBC & & BMC & TBC \\
\hline Birth weight & $0.83^{*}$ & $0.94^{*}$ & & 0.35 & $0.50 \dagger$ \\
Body weight & $0.65 \ddagger$ & $0.90^{*}$ & & 0.42 & $0.59 \ddagger$ \\
Crown-rump length & $0.75^{*}$ & $0.85^{*}$ & & 0.38 & $0.56 \dagger$ \\
Serum P & -0.19 & -0.41 & & $0.58 \dagger$ & $0.58 \dagger$ \\
Serum AP activity & 0.37 & 0.31 & & $-0.49 \dagger$ & -0.45
\end{tabular}

$* p<0.001$.

$\dagger p<0.05$.

$\ddagger p<0.01$. 


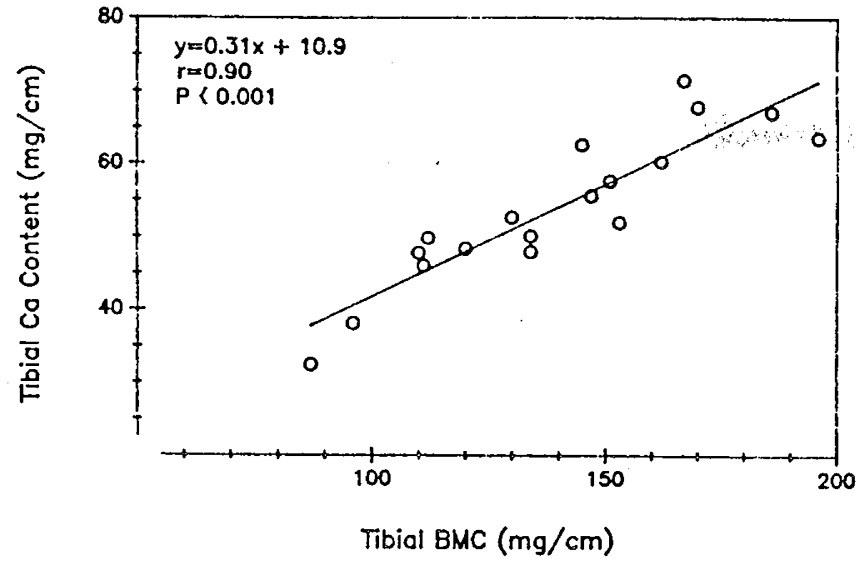

Fig. 2. Relationship between BMC and chemical calcium content at the mid-tibia in 19-day-old miniature piglets, $\mathrm{r}=0.90, p<0.001$.

alkaline phosphatase activity significantly increased the predictability of TBC by BMC.

\section{DISCUSSION}

We observed that limb measurements of BMC were correlated significantly with total body calcium in neonatal miniature piglets. Calcium content at the mid-tibia also was reflected accurately by BMC. Total body calcium was predicted best by BMC when compared with predictions by serum calcium, phosphorus, or alkaline phosphatase activity. Growth was a poor predictor of mineral status during the first $3 \mathrm{wk}$ of life in the neonatal piglets studied.

Growth in all piglets was similar despite differences in mineral intakes. Higher correlations were found between BMC or TBC and body weight or CR length before dietary mineral restrictions were instituted at 6 days of age than at the conclusion of the study (Table 2). These results are consistent with studies in infants (15) and piglets (16) that suggest that $\mathrm{Ca}$ and $\mathrm{P}$ deficiency does not restrict somatic growth during the early postnatal period. Intrauterine accumulation of minerals apparently is adequate for somatic growth during this period. The correlations observed at 6 days suggest that body size cannot be dismissed when results of BMC measurements are interpreted.

We have reported recently that commonly used serum biochemical indices of mineral status have poor predictive value for BMC in growing premature infants (12). Alkaline phosphatase activity is affected by many factors, including normal growth and liver disease. Severe osteopenia has been reported in infants in the presence of a normal AP activity $(4,17,18)$. Regulation of serum calcium and phosphorus by vitamin $\mathrm{D}$, parathyroid hormone, and calcitonin may affect these measures independently of bone mineral status, Our results in neonatal miniature piglets suggest that these serum biochemical indices may not identify mineral deficiency adequately in infants. Additional indices, such as serum osteocalcin and urinary mineral excretion, require further evaluation.

Previous studies in which the relationship between BMC and TBC has been examined in adults have demonstrated a wide range of correlation coefficients $(5,6)$. In those studies, however, values for both $\mathrm{BMC}$ and $\mathrm{TBC}$ were far above the ranges found in infants. In our study, the range of BMC in the piglets at 19 days was equivalent to that reported in the humerus of newborn premature infants of 28-36 wk gestation (19) or the radius of term infants in the 1 st year of life (20). The total body calcium of the piglets at 19 days of age $(10-20 \mathrm{~g})$ is equivalent to that of the 31- to 35-wk human fetus (21).
Our results support the use of single photon absorptiometry for accurate measures of BMC in piglets. Although the rates of growth and bone mineralization in piglets are more rapid than those in human infants, the correlation between BMC and TBC over a range of measurements in the piglets was similar to that found in premature infants. This comparability suggests that single photon absorptiometry would be a useful assessment technique in infants. Whether the relationship between BMC and TBC is influenced by effects of endocrine factors, early weightbearing, and the mineralization patterns at diverse sites has yet to be clarified.

Acknowledgments. The authors thank M. Daniels, D. Barber, L. Costello, J. Kosanovich, N. Mehta, R. Shypailo for technical assistance; E.O. Smith, Ph.D., for statistical review; E. R. Klein for editorial review; and D. M. Reid for preparation of the manuscript.

\section{REFERENCES}

1. Von Sydow G 1946 A study of the development of rickets in premature infants. Acta Paediatr Scand 33(suppl 2):7-122

2. Health and Public Policy Committee, American College of Physicians 1984 Position papers: radiologic methods to evaluate bone mineral content. Ann Intern Med 100:908-911

3. Steichen JJ, Gratton PAC, Tsang RC 1980 Osteopenia of prematurity: the cause and possible treatment. J Pediatr 96:528-534

4. James JR, Congdon PJ, Truscott J, Horsman A, Arthur R 1986 Osteopenia of prematurity. Arch Dis Child 61:871-876

5. Cohn SH, Ellis KJ, Wallach S, Zanzi I, Atkins HL, Aloia JF 1974 Absolute and relative deficit in total-body skeletal calcium and radial bone mineral in osteoporosis. J Nucl Med 15:428-435

6. Christiansen C, Rodbro P 1975 Estimation of total body calcium from the bone mineral content of the forearm. Scand J Clin Lab Invest 35:425-431

7. Greer FJ, Lane J, Weiner S, Mazess RB 1983 An accurate and reproducible absorptiometric technique for determining bone mineral content in newborn infants. Pediatr Res 17:259-262

8. Dickerson JWT 1962 The effect of development on the composition of a long bone of the pig, rat and fowl. Biochem J 82:47-55

9. Dickerson JWT 1962 Changes in the composition of the human femur during growth. Biochem J 82:56-63

10. Filer LJ, Fomon SJ, Anderson TA, Anderson DW, Rogers RR, Jensen RL 1973 Growth, serum chemical values and carcass composition of PitmanMoore miniature pigs during the first eight weeks of life. J Nutr 103:425437

11. Baskett R 1969 The nutrient requirements of farm livestock, part 3: Pigs. In: Cuthbertson D (ed) International Encyclopedia of Food and Nutrition: Nutrition of Animals of Agricultural Importance, Part 2. Pergamon Press, Oxford, 17:1096-1135

12. Abrams SA, Schanler RJ, Garza C 1988 Bone mineral content in former very low birth weight infants fed either human milk or formula. J Pediatr 112:956-60

13. Sheng HP, Huggins RA, Garza C, Evans HJ, LeBlanc AD, Nichols BL, Johnson PC 1981 Total body sodium, calcium, and chloride measured chemically and by neutron activation in guinea pigs. Am J Physiol 241:R419-R422

14. Schanler RJ, Garza C, Smith EO 1985 Fortified mothers' milk for very low birth weight infants: results of macromineral balance studies. J Pediatr 107:767-774

15. Schanler RJ, Abrams SA, Garza C 1988 Bioavailability of calcium and phosphorus in human milk fortifiers and formula for very low birth weight infants. J Pediatr 113:95-100

16. Miller ER, Ullrey DE, Zutaut CL, Baltzer BV, Schmidt DA, Hoefer JA, Luecke RW 1962 Calcium requirement of the baby pig. J Nutr 77:7-17

17. Lyon AJ, McIntosh N, Wheeler K, Williams JE 1987 Radiological rickets in extremely low birthweight infants. Pediatr Radiol 17:56-58

18. Walters EG, Murphy JF, Henry P, Gray OP, Elder GH 1986 Plasma alkaline phosphatase activity and its relation to rickets in pre-term infants. Ann Clin Biochem 23:652-656

19. Vyhmeister NR, Linkhart TA, Hay S, Baylink DJ, Ghosh B 1987 Measurement of bone mineral content in the term and preterm infant. Am J Dis Child 141:506-510

20. Greer FR, Searcy JE, Levin RS, Steichen JJ, Steichen-Asche PS, Tsang RC 1982 Bone mineral content and serum 25-OHD concentrations in breastfed infants with and without supplemental vitamin D: one year follow-up. J Pediatr 100:919-922

21. Widdowson EM, Dickerson JWT 1964 Chemical composition of the body. In: Comar CL, Bronner F (eds) Mineral Metabolism. Academic Press, New York, 1-207 